\title{
Cost-Effective Micro Hybrid Power Plant with Rational Fuel Feeding Arrangement
}

\author{
Gurinderpal Singh ${ }^{1},{ }^{2}$ V.K. Jain and ${ }^{3}$ Amanpreet Singh \\ ${ }^{1}$ Research Scholar, Sant Longowal Institute of Engineering\& Technology \\ gurinderbrar423@gmail.com \\ ${ }^{2}$ Professor, Department of Electrical and Instrumentation Engineering, \\ SLIET, Longowal, Punjab, India. \\ ${ }^{3}$ Assoc. Professor, I.K.G. Punjab Technical University, Kapurthala, Punjab.
}

\begin{abstract}
This case study proposes the hybrid system for stability, wherein the electricity generation is facilitated by a solar photovoltaic and biogas system for generation of electricity. This study pays utmost attention towards evading the adverse effects from global warming and meeting the resource demands. The hybrid system energy renders cost-effectiveness with improved reliability and life quality in smaller towns and scattered population, where the distribution of energy becomes costly and efficiency is reduced so to overcome this problems we try to design a hybrid system which will meet our demand and will be environmental friendly. This process of hybrid energy is a new concept and it is expected that it has great future. As today's world needs energy and the energy should be environmental friendly and it should reach each and every person throughout the globe. Therefore to meet this type of demand we have to see what type of non conventional resources are available in which part and depending on this we have to design the generation of energy. As we know that any of the non conventional source is not $100 \%$ reliable so to increase the reliability we go in for hybrid energy. In this system we use different sources of non conventional energy resources in combination. The different combinations are different for different reasons. In this case we take the case of Punjab reign of India in sub continent of Asia, Which is an intensive agricultural state and location wise it is located where we get good amount sunlight around the year. So in this we use the combination of solar and biogas energies to meet our demand of a stable reliable and environmental friendly energy.
\end{abstract}

Keywords- Hybrid System, Renewable Energy, Reliability, Environmental friendly

\section{INTRODUCTION}

Different forms of Non conventional energy sources.

1. Bio Energy (Biogas and Biomass)

2. Geo Thermal Energy

3. Wind Energy

4. Solar Energy

5. Tidal Energy

Due to the new regulations about self production of energy from renewable sources of energy we are concentrating on above stated different sources of energy [1] [2]. Depending on these sources availability at any part of the world, we are trying to have our energies from above stated sources [21]. But due to some technical problems of these sources individually we are not able to depend on them reliably for energy [22]. As we have two parts of energy load, the peak load as well as the base load now depend on different sources we try to generate or have a hybrid source to meet our base load and peak load together [12]. Now depending on the availability of the non conventional sources we have different combinations in different regions example could be solar with wind, solar with biomass, solar with biogas wind with tidal, wind with biogas, tidal with biogas etc [3] [4] [5] [23] [24] [25] [26]. Depending on the conditions of north India, which has large amount of solar energy and large rural population with huge number of domestic animals, it is essential to exploit the solar energy. So, this paper focuses on the combination of biogas and solar energy to show that we can attain self reliability at the village level or a cluster of few villages.

\section{A. Bio-Energy}

The organic carbon based material of plants and animals is called biomass. This biomass probably gets converted into bio-fuels through physical, biological and chemical processes [8] [13]. In chemical form biomass is stored solar energy and can be converted into solid, liquid and gaseous energy carries as shown in Fig. 1.1. (The dry matter of biological material cycling the bio-sphere ranged $250 \times 10^{9} \mathrm{t}^{-1}$ with the carbon inclusion of 
$100 \times 10^{9} \mathrm{ty}^{-1}$. The energy that the process of photosynthesis involved is $2 \times 10^{21} \mathrm{~J} \mathrm{y}^{-1}$. Of this, a percentage of 0.5 by weight is the biomass used for human food). The careful utilization of bio-fuels within the natural ecological cycles will possibly result in pollution-free environment with greater sustainability. The energy obtained from the bio-fuels is called the bio-energy. The bio-gas technology dealing with bio-chemical route of bio-energy is called biomethanation.

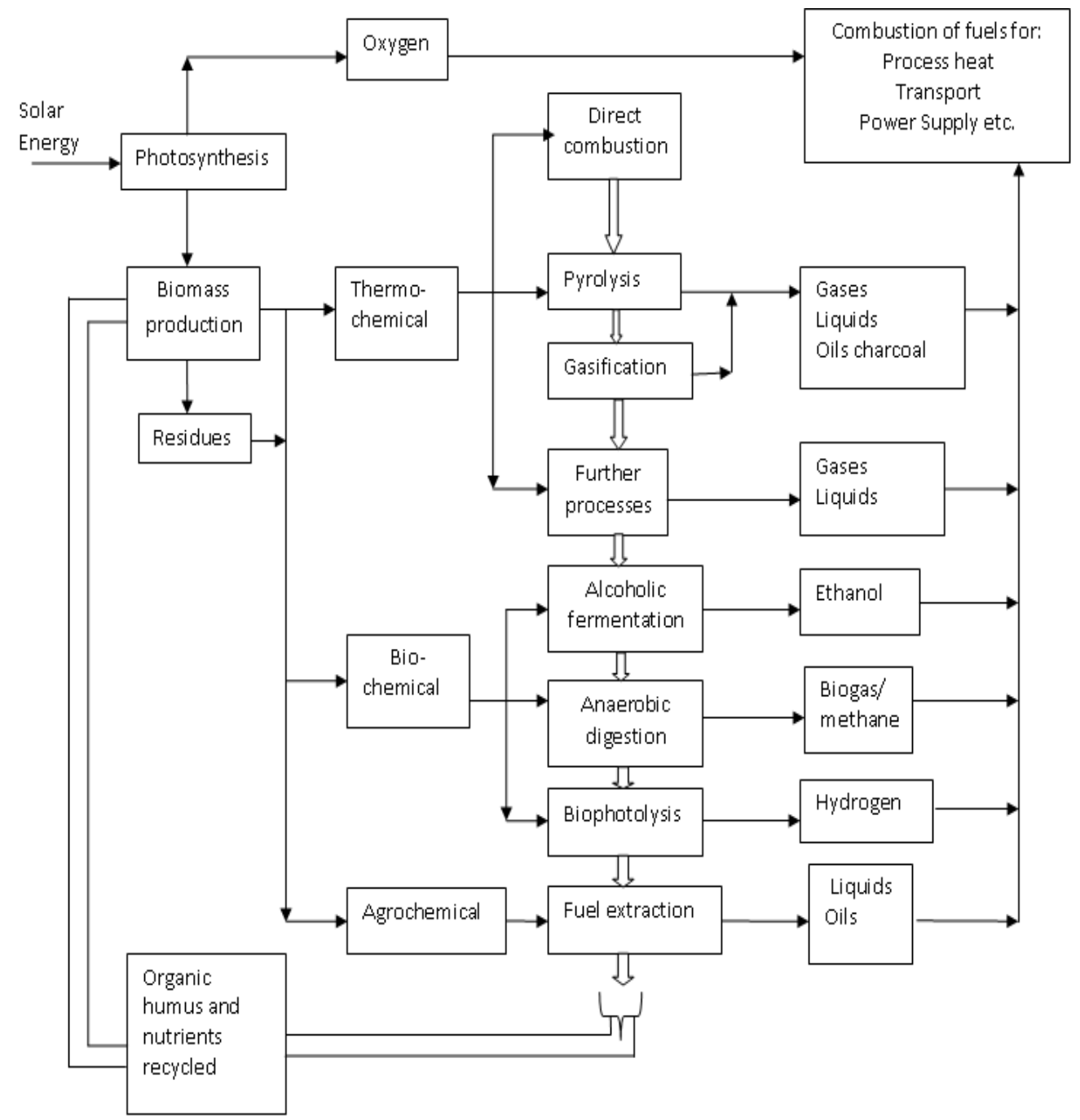

Fig. 1. Solar Energy a conversion to Biomass

\section{B. Solar Energy}

The upper atmosphere of the earth is subjected to an incoming solar radiation (termed as, insolation) of 174,000 TW (TerraWatts), in nature. The landmasses, oceans and clouds absorb about 70\% of this solar radiation quantity, leaving the rest (around 30\%) to return back to the space by means of reflection. The solar light, which falls closer to the surface of the earth, has its spectrum to lie around the visible as well as the nearinfrared regions in a wider sense. In contrast, the spectrum encloses the near-ultraviolet region by a smaller part [9] [10]. The people all around the globe, for the most part, have their living regions with 3.5 to $7.0 \mathrm{kWh} / \underline{\mathrm{m}^{2}} / \mathrm{day}$ or 150 to 300 watts per square meter insolation levels.

Converting solar energy into other forms of energy is done by two methods.

A. Solar Photovoltaic method
B. Solar thermal method

\section{Wind Energy}

Wind power is the outcome of wind turbines, wherein mechanical/electric power is produced through wind energy conversion [6]. Rapidly moving blades with torque-exerted rotors are blown with wind to achieve wind extraction [7]. It is the speed of wind and rotor dimensions that decide the transferred power quantity. The wind turbines for residential exploitation can be as tiny as a 400 watt generator, while the offshore regions or wind farms may have the size ranges of wind turbines as large as megawatt machines [11]. In case of the tiny wind 
turbines, a vane for wind pointing, life time bearings, aero elastic blades, direct current output and directlydriven generators are usually available. In contrast, active wind pointing, flaps, alternating current outputs and geared power trains are associated with the mega-sized wind turbines [18]. Especially, in the large-sized wind turbines, aeroelastic blades and direct drive generators have frequent usage than the direct current generators [19]. The capacity factor decides yearly energy generation of a wind converter, owing to the variable nature of wind speed. The capacity factor is about $35 \%$ for a wind generator that is suitably positioned. This factor of capacity is comparable with the thermal plants, coal plants and nuclear plants, where the associated capacity factors are $30 \%, 70 \%$ and $90 \%$, respectively. The basic necessity of an area for wind generator positioning is that it should be prone to a wind speed of not less than $4.5 \mathrm{~m} / \mathrm{s}$, on an average [20]. Normally, the wind atlas makes the initial choice of the site for wind generator positioning. However, the wind measurements on the chosen site have to be made prior to generator positioning to know the wind quantity and the other associated factors of wind generation. The wind energy can better substitute the electricity from fossil fuel manipulation, since it is in abundant in a widely-spread manner with increased cleanliness and cuts down the greenhouse gas emissions. The wind's sporadic nature never causes issues, even when the wind power is subjected to small or reasonable levels of penetration.

\section{Geo-thermal Energy}

The thermal energy, which the earth generates and stores, is termed as the Geo-thermal energy. The energy, which is associated with a matter's hotness, is called the thermal energy. The earth crust has been subjected to geothermal energy generation naturally, at the time of planet formation itself or during the process of radioactive material decay. The difference of the planet's surface from its core temperature is termed as the geothermal gradient and it is responsible for the non-stop thermal energy conduction between the core and the surface, in terms of heat. The term 'geothermal' is an adjective that has its origination from Greek because 'geo' and 'thermo' are Greek terms that meant earth and hot, respectively. Thus, the internally developed heat of the earth because of radioactive decay or the incessant loss of heat that is produced during earth's origin is called as the thermal energy. Generally, the boundary between the core and the mantle may sometimes exhibit a temperature that is as high as $4000{ }^{\circ} \mathrm{C}\left(7,200^{\circ} \mathrm{F}\right)$. Melting of solid mantle as well as rocks becomes more frequent, at such high temperatures or pressures of interior earth. Once the solid mantle or the rocks get melted, the rocks cause few mantle portions to face convexly up because of the mantle's dense nature than the rocks around it. Within the crust, the heating of water as well as rock takes place at temperatures that is as high as $370{ }^{\circ} \mathrm{C}\left(700{ }^{\circ} \mathrm{F}\right)$. The geothermal energy, as hot springs, was utilized for space heating and bathing purposes during the prehistoric Roman times and Paleolithic times, respectively. But, nowadays, it is considered as a renowned source of electric power. As per the survey of 2013, about $11700 \mathrm{MW}$ of electric power that was consumed all around the globe resulted from processing the geothermal energy. In 2010, geothermal power of about 28 gigawatts was deployed chiefly for agricultural applications as well desalination, industrial processing, spas and space as well as district heating. Though geothermal energy renders increased sustainability, cost-effectiveness, ecofriendliness and reliability of power, its utilization is restricted to regions that are so close to the boundaries of tectonic plate.

\section{E. Tidal Energy}

Tidal power/energy results from the energy, which the moving water of open ocean currents and tides exhibit. The tidal energy extraction involves extracting two kinds of energy and they are: (i) potential energy, resulting from the difference of height of the lower tide from the higher tide and (ii) kinetic energy, resulting from the water in motion of river, open ocean currents and tides. Kinetic energy-extracting tidal energy system has acquired greater salutation among people, since it is imagined to be a harmless energy acquiring system that never affects dams/barrages.

So far, a number of areas near the coast have been investigated for its fitness of extracting tidal power. The tidal power also comes under the category of renewable source of energy, as does the hydroelectric power. The reason is its inexhaustible nature and further, the source of tides is the orbital mechanism of the solar system. Moreover, the wind's surface effects are responsible for the generation of ocean currents. The tidal energy has its chief root from the orbital kinetic energy, which is associated with the system involving the earth as well as the sun and the earth as well as the moon. The future generations can better rely on tidal power for their electricity demand because the aforesaid rotational systems possess abundant, but boundless, energy within them. Moreover, the reliability prediction is high for the tidal power than the power generated from sun or wind. The tide mills of Europe have been functioning for about thousand years, especially to grind the grains. The modern-day tide mills render tidal stream power.

\section{LITERATURE REVIEW}

A. Gupta et al. have presented a paper entitled, "Design of an Optimal Hybrid Energy System Model for Remote Rural Area Power Generation" [1].The authors put forth an energy system , which hybridized 
micro/small hydro, biomass, photovoltaic and wind powers, for incessant power supply of loads. Further, they estimated the capital cost through an economic analysis. The optimized cost from their proposed system was compared against the energy cost from several other resources, to confirm its superiority.

Ajai Gupta et al. have presented a paper entitled, "Computerized Modelling of Hybrid Energy System Part I: Problem Formulation and Model Development" [2]. The authors' intention was to support the people of the remotely-located rural areas by rendering them a hybrid energy system with enhanced reliability, costeffectiveness and life quality. The hybrid system owned suitable techniques for its functioning as well as better dispatch controlling units, in order to meet the economic constraints. In the initial part of the tri-series paper, a mixed integer linear mathematical programming model was analyzed, prior to designing. This model was specifically used to achieve an optimal cost as well as operation in an energy system, involving a fossil fuel generator, a battery bank, micro/small hydro, biomass and photovoltaic array. Here, the cost function minimization was subjected to the potential as well as the demand constraints. They also dealt with the mathematical modelling of various functioning units in the hybridized energy system. Here, the Indian rural regions that were remotely-located were used for power generation purposes. This hybrid energy system is imagined to function properly in rest of the rural regions, all around the world.

Alexandre Barin et al. [3] have made an examination on the way of encountering the heavy energy utilization, along with the adverse impacts of pollution. In their search for an effective and an eco-friendly renewable resource, they found biomass to be a better and widespread pollution-free resource of renewable energy [14] [15] [16]. In this paper, they achieved a controlled production of biogas through letting the livestock manure to be degraded by the action of anaerobic digesters. They employed the fuzzy multi-sets as well as the multi-rules for assessing the operating characteristics of the biogas energy source. Their method was also adopted in the energy storage domain for inventing the highly suitable biogas-fuelled renewable hybrid system. The parameters that directed their investigation were: operational temperature, cogeneration, range of power application, technical progress, life cycle, expense, efficiency and environmental effects. Of these parameters considered, utmost interest was shown towards environmental conditions and the associated expense.

Ajai Gupta et al. [4] have met the load demand in a nine village-containing remotely-located rural region by applying the model of battery storage-type hybrid energy system, which was developed in the first tri-series, and simulating it based on the algorithm found in the second tri-series. Using the simulation outcomes, which were observed during each hour, the system operation was simulated for a span of one month. The data, which correspond to the solar isolation of every hour and load, served as the inputs for simulation. The hybrid energy system underwent cost optimization, in terms of hours, days and months and economic analysis was also carried out. The simulation outcomes aided the energy planners to contribute an improved hybrid energy system in Uttarakhand.

\section{DISCUSSION}

Now we start the discussion on solar and bio power plant layout individually which are explained by the schematic layout plans below:

\section{A. Schemetic Layout Plan for Micro Solar Photovoltaic Power Plant}

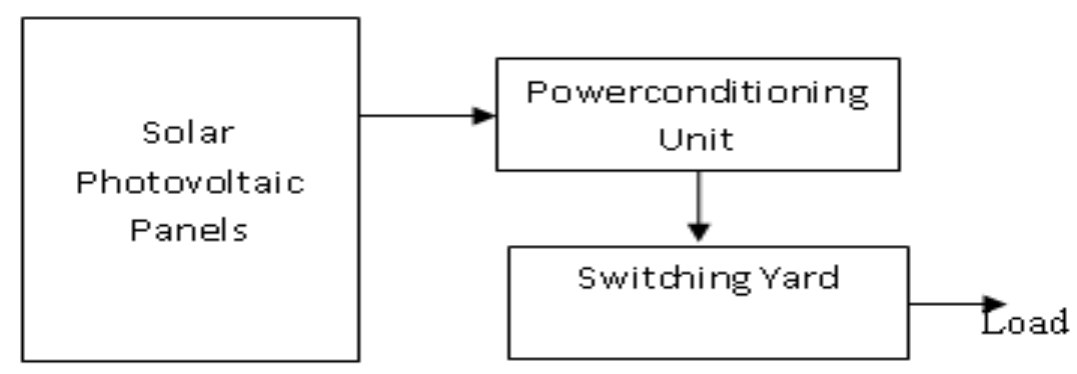

03.00

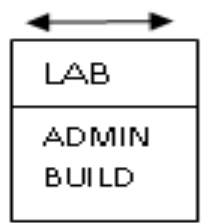

Fig. 2. Schemetic Layout Plan for Micro Solar Photovoltaic Power Plant 
B. Schematic Layout for Micro Solar Thermal Power Plant The total cost of power plant $=X$
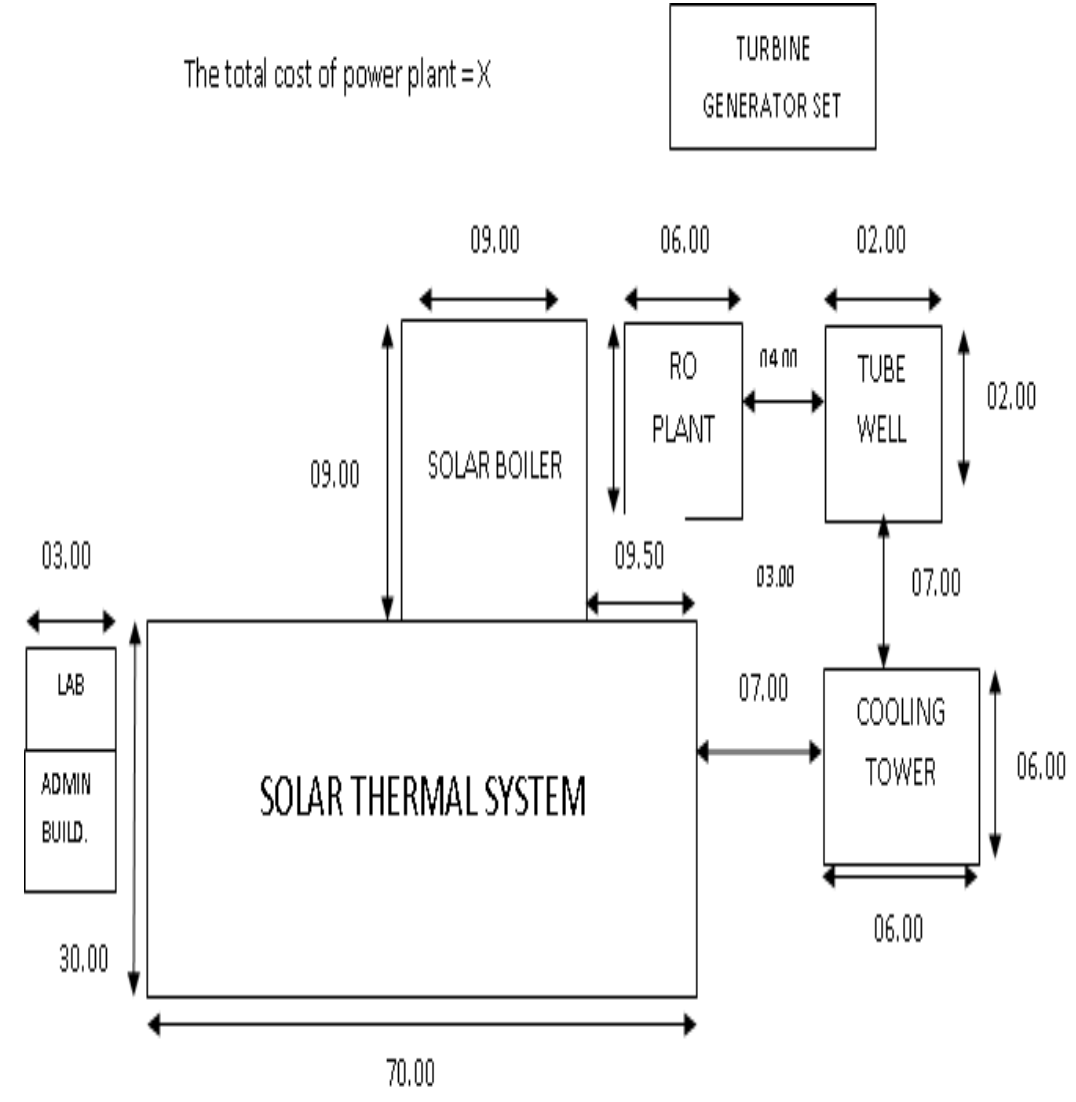

Fig.3. Schematic Layout for Micro Solar Thermal Power Plant

C. Schematic Layout for Micro Bio Mass Power Plant

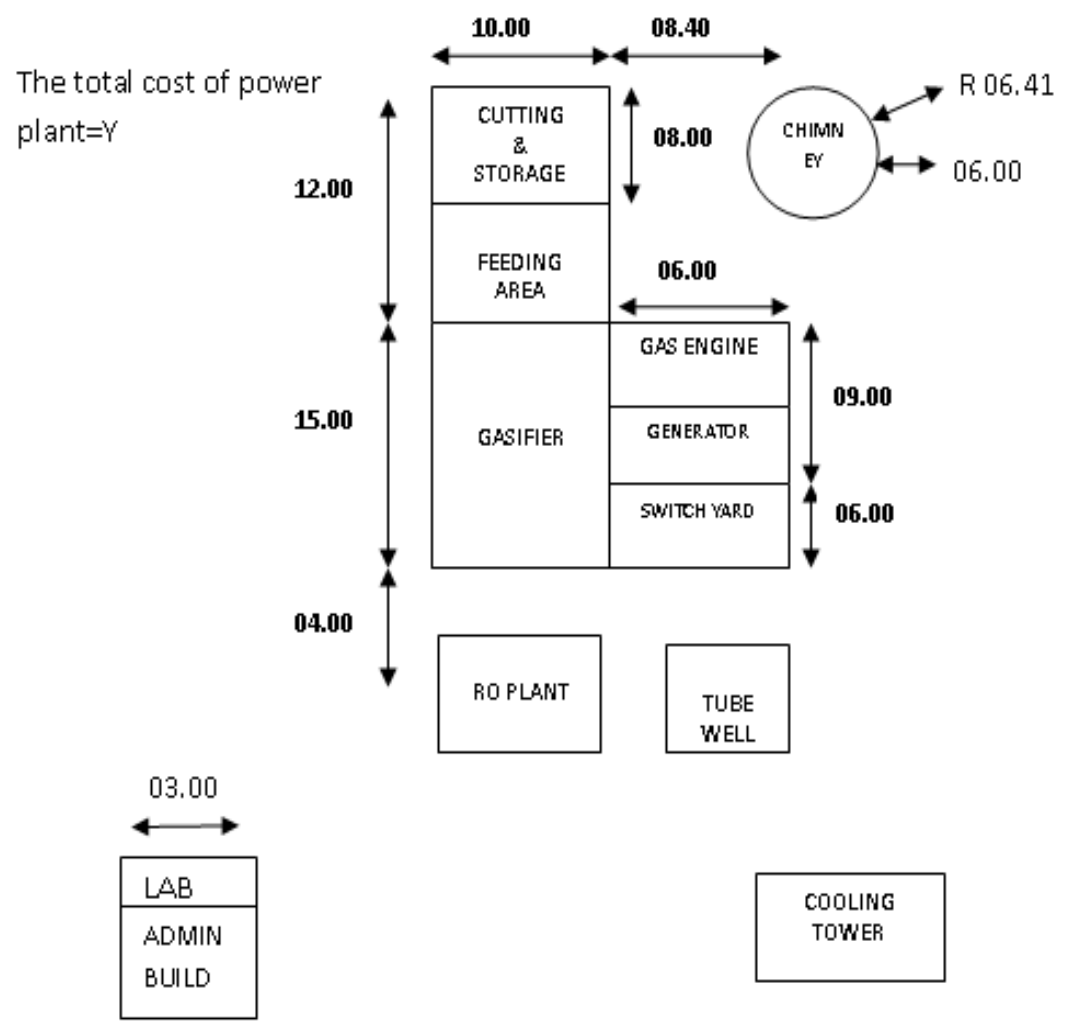

Fig.4. Schematic layout for micro bio mass power plant 

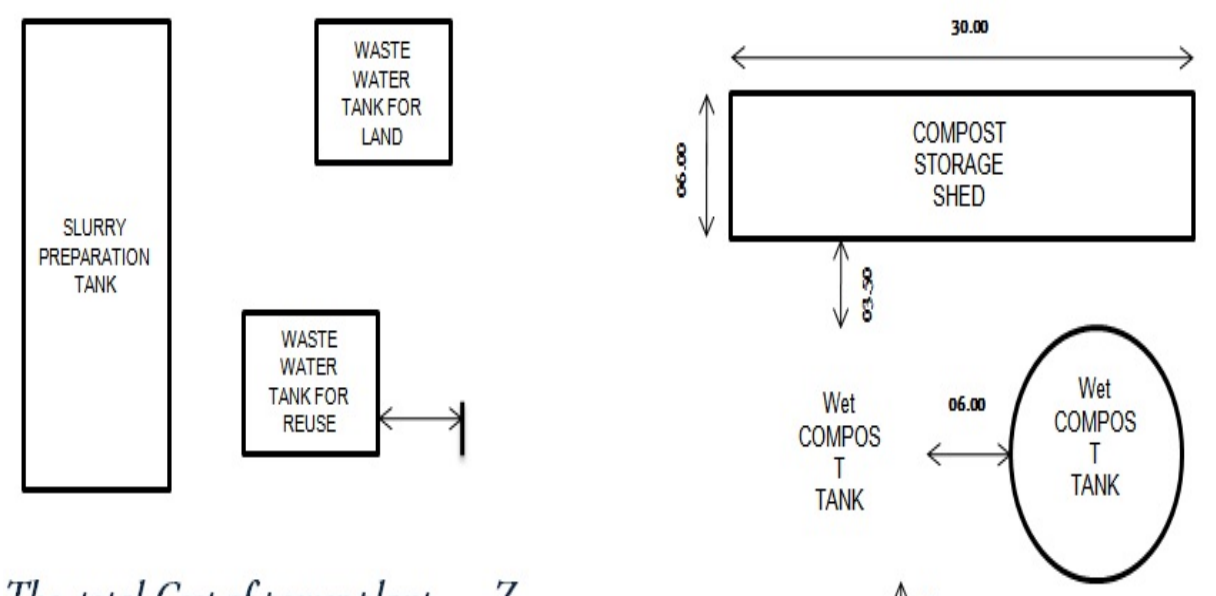

\section{The total Cost of power plant $=Z$}

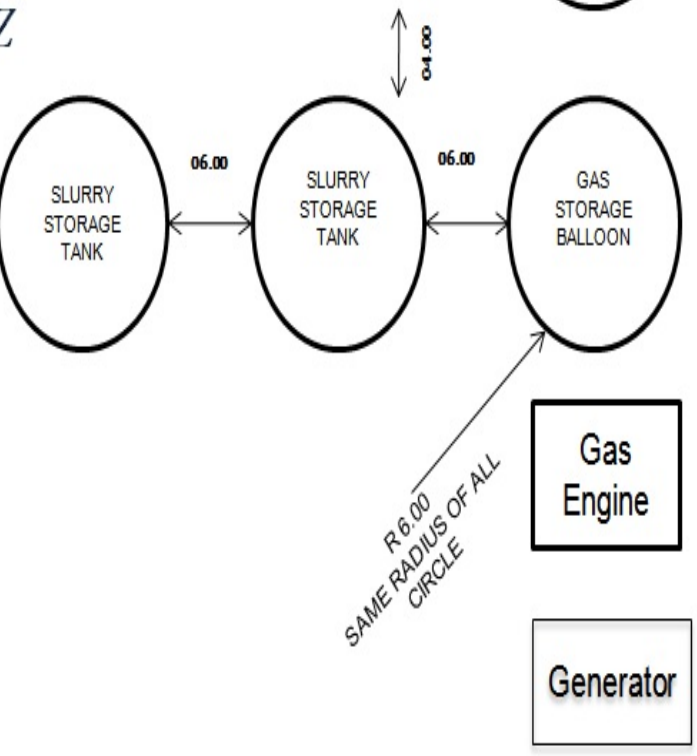

Fig. 5. Schematic Layout for Micro Bio - Gas Power Plant

\section{Disadvantages of Single Resource Fuel Input System}

All single resource fuel input power plants have their own reasons for overall poor performance hence disadvantageous. e.g.

1. Solar thermal fuel cannot be used after sunset, the heat preservation arrangement is must for 24 hour power generation, possibly at substantial increased cost .

2. Bio-gas production in sufficient quantity will require large quantity of cow dung, kitchen waste etc . Moreover rearing of proportionately large number of cattle and their dung collection is a problem in itself

3. The procurement, transportation and storage of bio-mass in required quantity has many problems .The ash disposal is bigger problem for a power plant more than $250 \mathrm{kw}$

Similar rules apply to other non- conventional resources such as photovoltaic, wind, geo-thermal .

So the Algebraic Formulae should be applied to overcome the drawbacks and to ensure 24 hour power generation.

\section{HYBRID PLANT}

Hybrid power plant is a hybrid combination of available sources of energy at particular point and particular place so accordingly we make the combinations of the sources for the energy generation which is reliable and cost efficient so based on this we start our discussion of available energies of different types depending on how long it is available and the quantity required for it. So we start the discussion of a micro hybrid power plant which will consist of solar energy biomass and biogas which can be collected/obtained at that village level of any of the village of Punjab state(India).

\section{A. Village Level, Optimum Size of Micro Hybird Power Plant}

Fuel requirement for $100 \mathrm{Kw}$ power plant

Solar Thermal: Available for 6 hours on an average 
Photovoltaic: Available for 6 hours on an average

Requirement BIO-MASS: $1.5 \mathrm{Kg} / \mathrm{Kwh}$

$$
\begin{aligned}
& \text { Daily } 1.5 \text { X100X24 }=3600 \mathrm{Kg} \\
& \text { Monthly } 3600 \times 30=108000 \mathrm{Kg} \\
& \text { Yearly } 108000 X 12=1296000 \mathrm{Kg}
\end{aligned}
$$

Available Bio-Mass: Cotton Stalks $-1500 \mathrm{Kg}$ /acre

Mustard - $1200 \mathrm{Kg} /$ acre

Guar Residue $-1500 \mathrm{~g} / \mathrm{acre}$

Ash content : 6 to $10 \%$ (most of it is Potash)

Paddy Residue $-2400 \mathrm{Kg} /$ acre

\section{Note:-1}

Bio-Mass - $3600 \mathrm{Kg}$ /day meaning 2 acre crop residue/day ,730 acre/year

(If the size of plant is increased to $250 \mathrm{Kw}$ it is 5 acre/day, 1825 acre/year).

Any village shall not have land more than $2000-2500$ acre.

If all the residue is to be exclusively used for this purpose (which is not possible) then a Bio-mass plant of $250 \mathrm{Kw}$ Capacity could be installed.

BIO-GAS: $\quad$ Cow Dung 30-35 Ton Daily

No of Cattle -3000 to 3500

Residue as Compost -4 Tone

\section{Note :-2}

Any village of 100 houses do not have 3000 - 3500 cattle, it is not possible to generate 24 hours power by using Dung only so, to produce sufficient quantity of bio-gas additional ingredients such as Kitchen waste etc shall have to be added.

From above it can be concluded that single resource power plant is not viable in any village but Hybrid power plant of $100 / 200 / 250 \mathrm{Kw}$ can be installed and operated with the available fuel in a particular village/ location.

\section{BOUNDARY OF ONE VILLAGE}

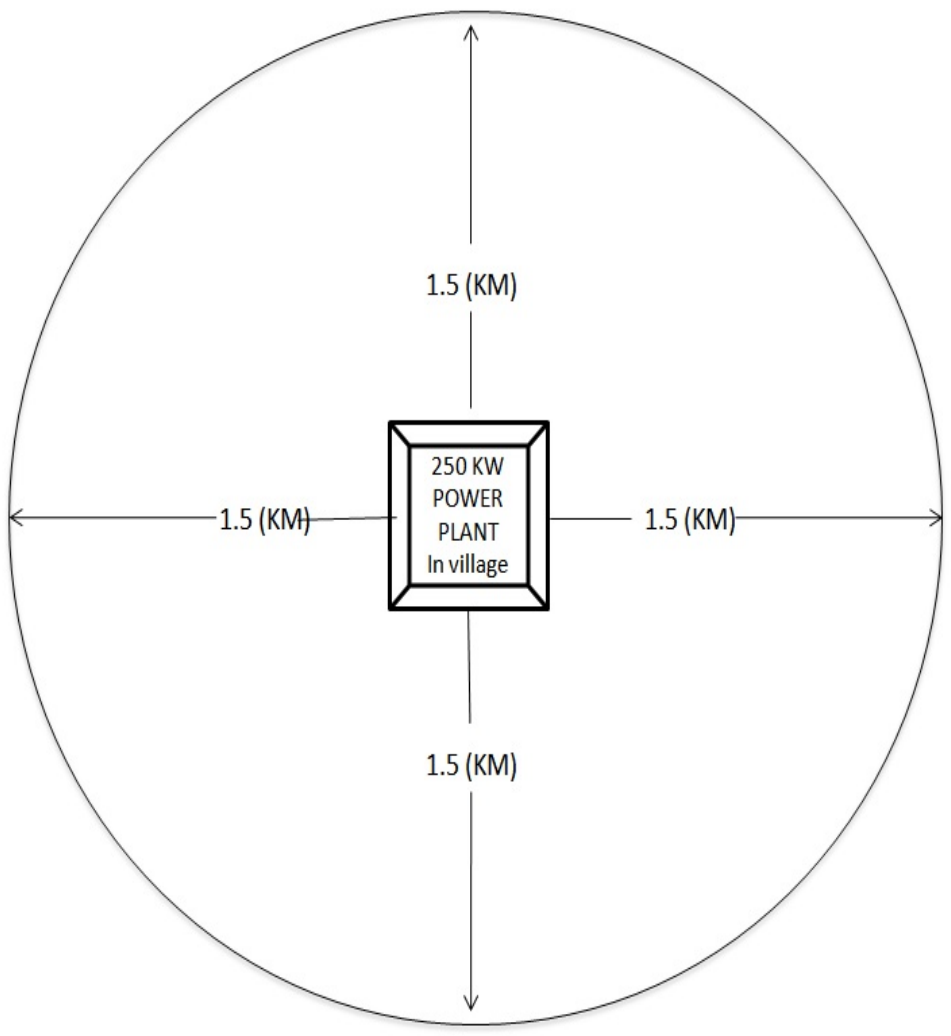

Fig. 6. Description of location of a power plant in a village with reference to other villages. 


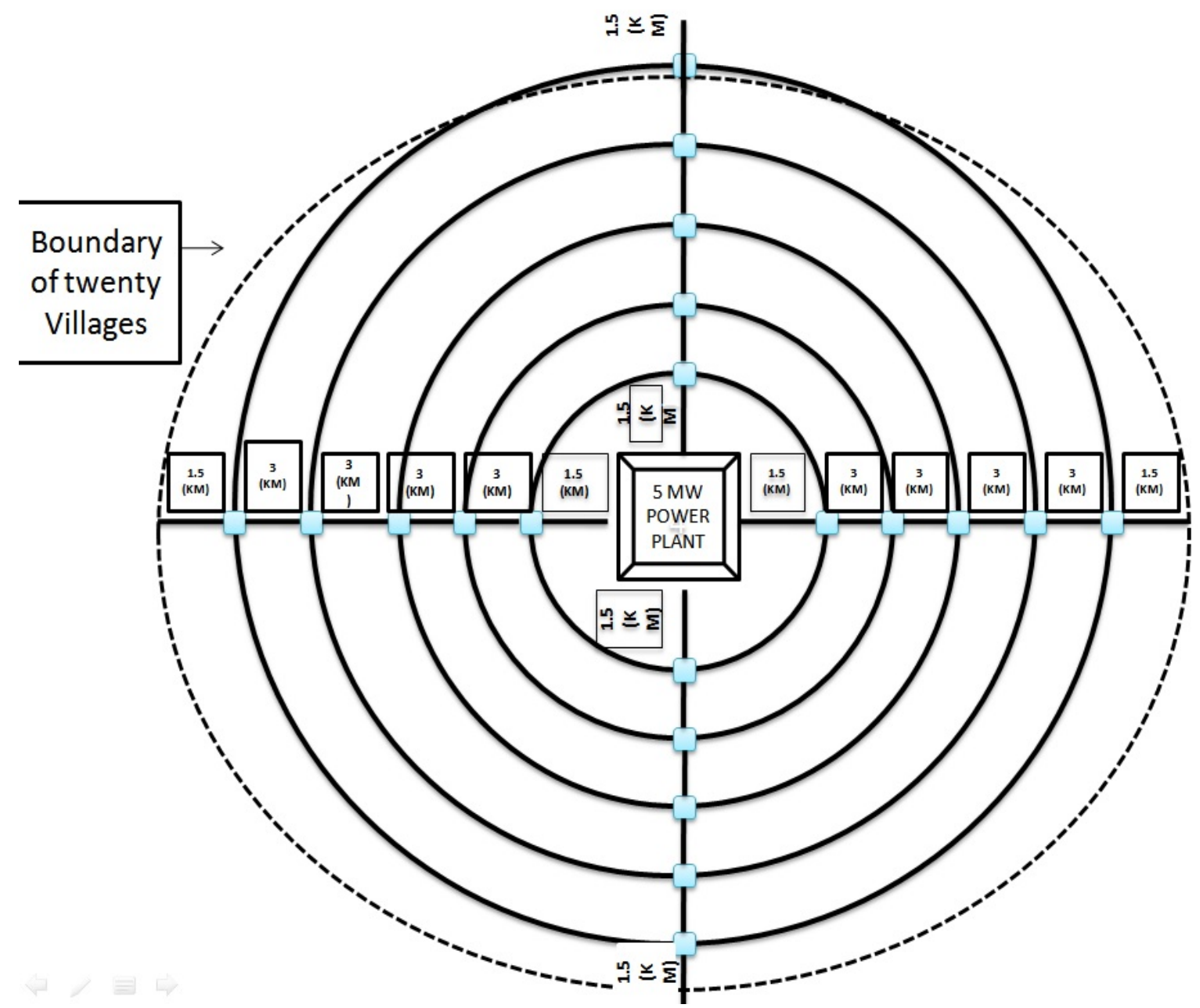

Fig. 7. Description of location of a power plant in a village with reference to other 20 villages(5 in each direction).

B. Comparision of Diesel Consumption for Transportation of Raw Material to Bigger Hybrid Power Plant VizA-Viz Village Level Micro Hybrid Power Plant

TABLE1

Comparison table

\begin{tabular}{|c|c|c|c|c|c|c|c|c|c|c|c|c|c|}
\hline $\begin{array}{l}\dot{z} \\
\dot{n}\end{array}$ & 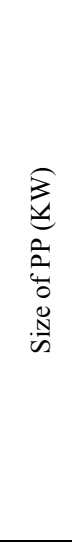 & 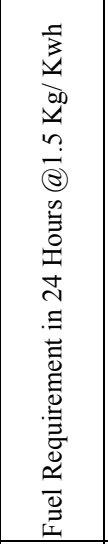 & 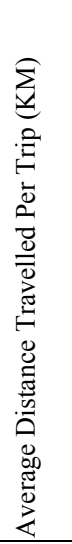 & 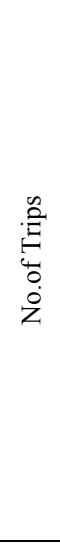 & 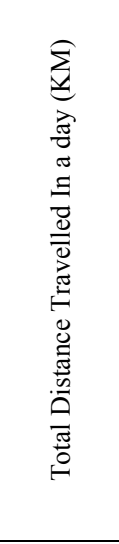 & 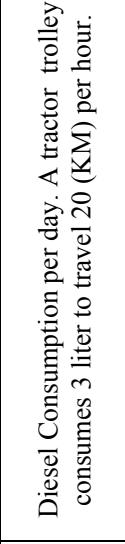 & 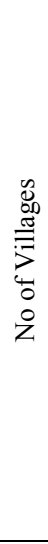 & 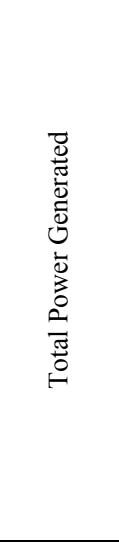 & 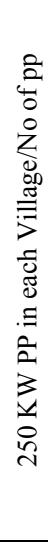 & 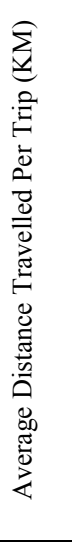 & 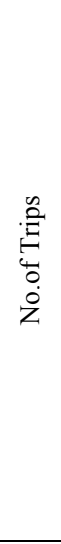 & 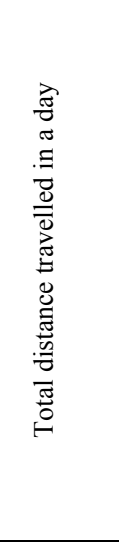 & 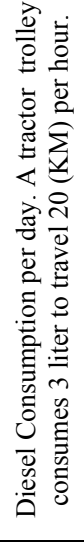 \\
\hline 1 & 250 & 9 Ton & 0.75 & 6 & $\begin{array}{c}(6 \times 0.75)= \\
4.5 \\
(\mathrm{KM}) \\
\end{array}$ & $\begin{array}{c}45 / 120=0 . \\
225^{*} \\
3=675 \\
\end{array}$ & 1 & $250 \mathrm{KW}$ & 1 & 0.75 & 6 & $4.5(\mathrm{KM})$ & 0.675 \\
\hline 2 & 1000 & 36 Ton & 1.5 & 24 & 36 & 5.4 & 4 & $1000 \mathrm{KW}$ & 4 & 0.75 & 24 & 18 & 2.7 \\
\hline 3 & 2000 & 72 Ton & 3 & 48 & $144(\mathrm{KM})$ & 21.6 & 8 & $2000 \mathrm{KW}$ & 8 & 0.75 & 48 & 36 & 5.4 \\
\hline 4 & 3000 & 108 Ton & 4.5 & 72 & 324 & 48.6 & 12 & $3000 \mathrm{KW}$ & 12 & 0.75 & 72 & 54 & 8.1 \\
\hline 5 & 4000 & 144 Ton & 6 & 96 & 576 & 86.25 & 16 & $4000 \mathrm{KW}$ & 16 & 0.75 & 96 & 72 & 10.8 \\
\hline 6 & 5000 & 180 Ton & 7.5 & 120 & 900 & 135 & 20 & $5000 \mathrm{KW}$ & 20 & 0.75 & 120 & 90 & 13.5 \\
\hline
\end{tabular}


For the same power generation, the Diesel consumption increases many folds in case of Larger Power Plant as compared to village level Power Plants. Thus, India will not be benefited.

Since more diesel shall be consumed which will increase carbon generation/ global warming, so World as a whole shall not get any benefit from non conventional power generation.

\section{Disadvantages of Hybrid Small Power Plant}

1. The land required for $1 \mathrm{MW}$ Power Plant is only 2 times the land required for 100-250 KW.

2. The capital cost of Bio- Gas \& Bio-Mass part shall not increase proportionately to the increase in size of Power Plant.

3. The number of employees shall increase for every Power Plant so the pay bill shall increase disproportionately.

\section{Algebraic Formulae}

The Algebraic Formulae for the of multi resource fuel input arrangement:

$$
C=X=\frac{(n-1) X_{7}+Y_{7}+Z_{7}+\ldots+n_{7}}{n}
$$

Any number of inputs are possible subject to:

$$
\begin{gathered}
X_{1}=Y_{1}=Z_{1} \ldots \ldots . .=n_{1} \\
X_{2}=Y_{2}=Z_{2} \ldots \ldots \ldots=n_{2} \\
\vdots \\
X_{6}=Y_{6}=Z_{6} \ldots \ldots . .=n_{6}
\end{gathered}
$$

\section{Where" $n$ "is number of inputs}

Note: If any of the conditions is not satisfied even then the formulae is applicable but the capital cost of the plant shall increase proportionately

\section{E. Schematic Layout Plan for Hybrid (Two Resource Fuel) Power Plant System}

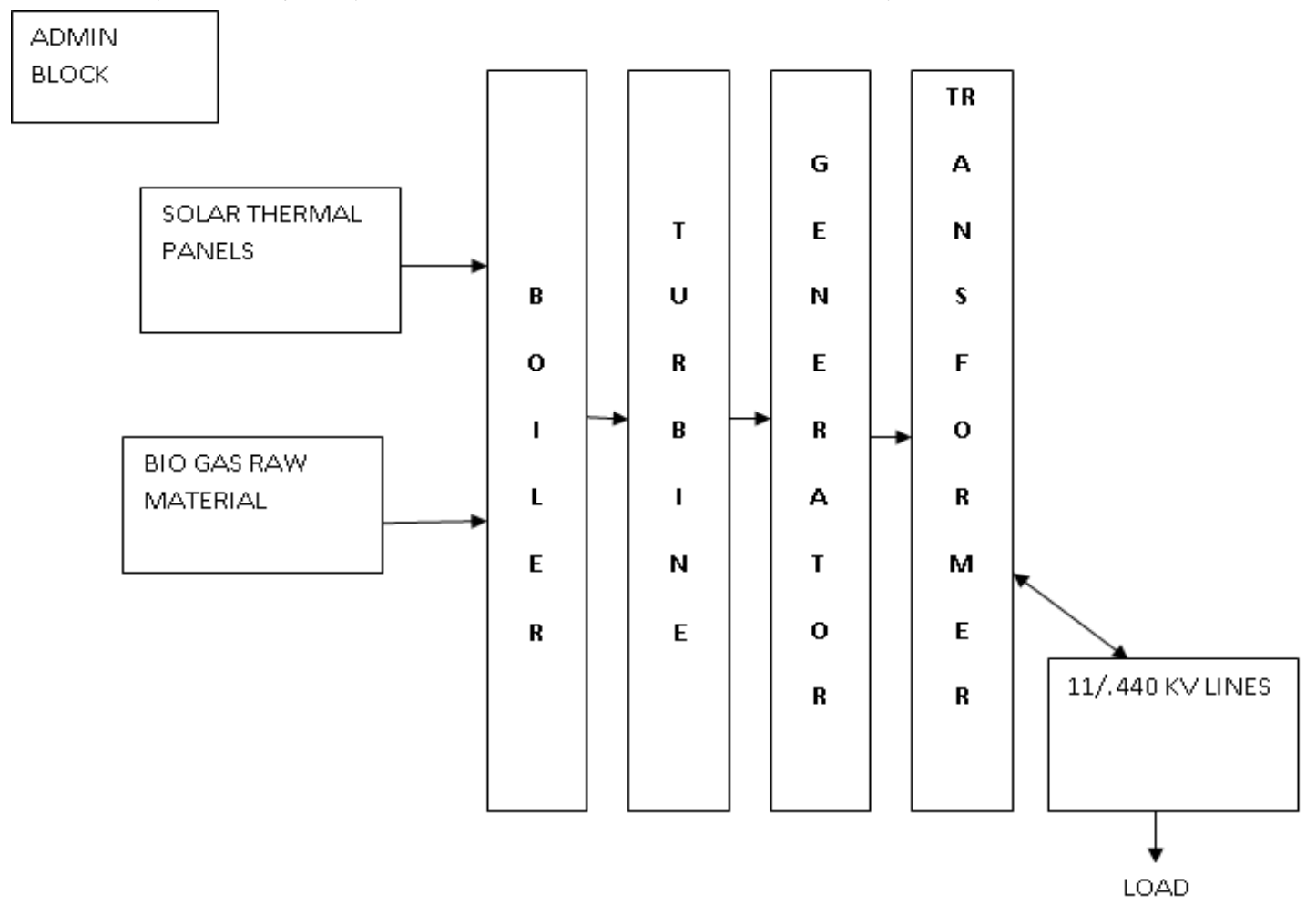

AUXILIARIES

Fig.7 Two fuel resource input arrangement 
More than two non-conventional resources of power are not available at same location in the world,( threefour resources are available in north Indian states only) so the rationale combination of two or more than two resources has not even been experimented),

Although the combination of bio-gas, bio- mass and solar thermal have not been tried anywhere in the world but the combination as per proposed ALGEBRAIC FORMULA shall be possible, which will be much more efficient, cost effective and successful by all means .

\section{Schematic layout plan for Three Resource Fuel input arrangement}

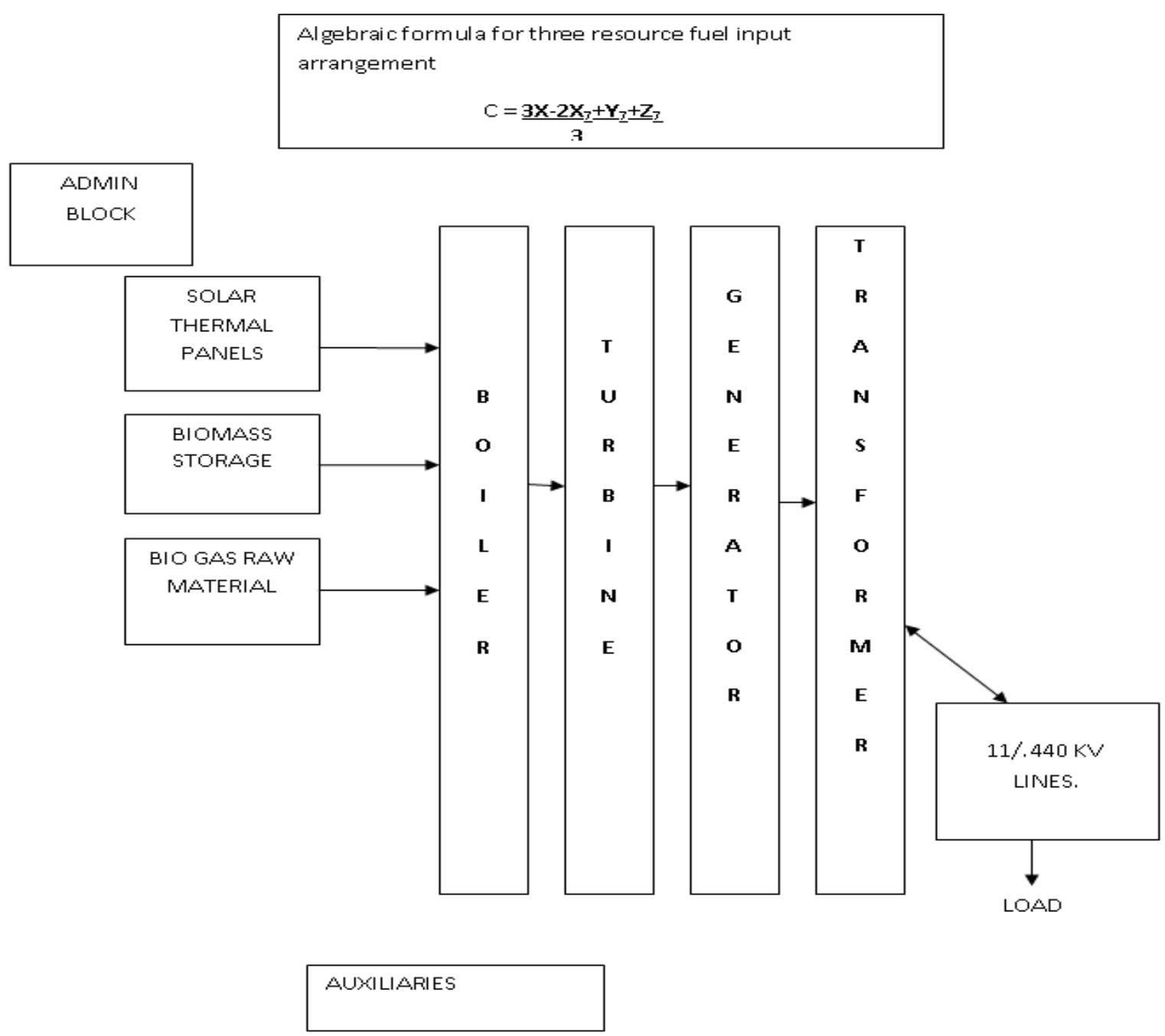

Fig.8 Three fuel resource input arrangement. 

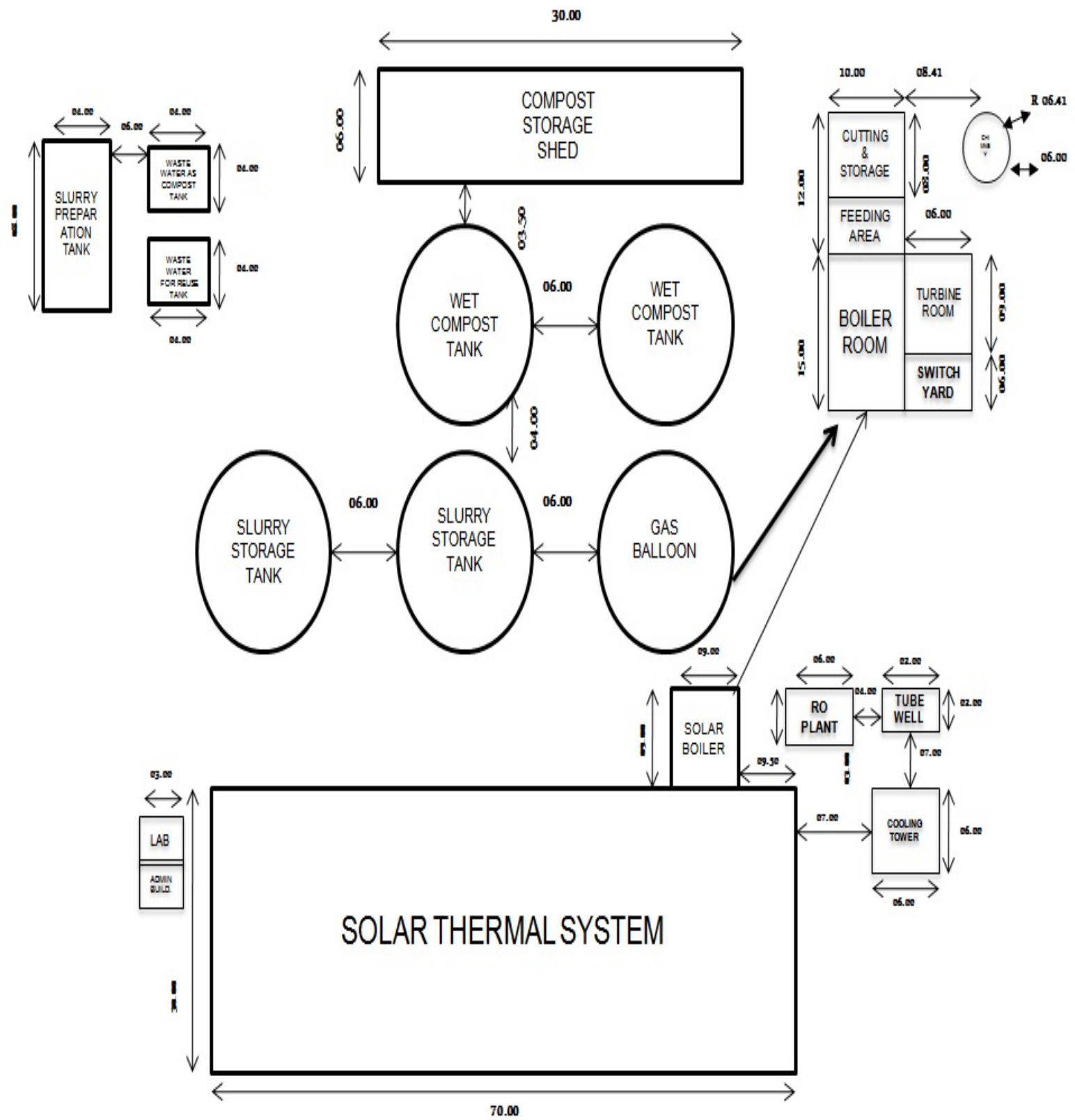

Fig. 9 Plan for three resource fuel input power plant

\section{G. Benefits of the Proposed Micro Hybrid Power Plant}

1. The gestation period of micro hybrid power plant is short (Six months Only) as compared to macro power plants (Two to Three Years).

2. Partial completion possible i.e. once one resource of energy work is completed, the power generation starts the second - third resources could be added later. This could be used as peak load generation.

3. The flexibility \& dependability increases with the increase in number of such power plants at village level.

4. No need of fuel storage as the fuel shall be available throughout the year, in the village itself

5. The power can be generated for 24 hour by using available fuel at any given point of time.

6. The residue such as ash, compost can be locally used by farmers, who shall be supplying cow dung and bio mass i.e. Husk, Straw of Rice, Wheat, Mustard or Green Fodder. Hence, production of crops will increase.

7. The arrangement shall clear the local area of heaps of cow dung etc, which shall further be beneficial for the health of local population. (No flies' mosquitoes etc). 
8. The public toilets (social welfare program) can be constructed in the premises of proposed station for bio gas production.

9. The project will generate local employment. The welfare scheme of Govt. of India such as MGNREGA will be logically implemented.

10. Reduction in green house gases (GHG) emission.

11. It will make Punjab, Haryana, U.P. and other Indian states independent of fossil fuels, to the larger extent.

12. Last but not least, by installing chiller plants for preservation and processing of milk at village level, the process of diversification of crops can be accelerated.

\section{CONCLUSION}

In the above research paper we have arrived at the conclusion that the all round development of the developing countries and specially the case of Punjab state (India) which is an agro based the possible best solution for the reliable clean energy and environment lies in the development of micro hybrid power plants. Due to this the advantages of small gestation period, no fuel storage throughout the year, power generation at the door step with a echo friendly development and generation of employment at the local level, due to which the development is throughout the state and not in the pockets which is a sign of overall development of society and not few individuals which is the target of all the democratic governments.

\section{REFERENCES}

[1] A. Gupta, R.P. Saini and M.P. Sharma "Design of an Optimal Hybrid Energy System Model for Remote Rural Area Power Generation” IEEE Electrical Engineering, ICEE. International Conference, Lahore, pp:1 - 6,11-12 Dec. 2007.

[2] Ajai Gupta, R. P. Saini, and M. P. Sharma "Computerized Modelling of Hybrid Energy System Part I: Problem Formulation and Model Development" IEEE 5th International Conference on Electrical and Computer Engineering ICECE ,pp:7 - 12, Dhaka, 20-22 Dec. 2008.

[3] Alexandre Barin, Luciane Canha, Alzenira Abaide, Karine Magnago, Breno Wottrich, "Renewable Hybrid Systems using Biogas Fuzzy Multi-Sets and Fuzzy Multi-Rules”IEEE Energy Conversion Congress and Exposition, 2009. ECCE. pp:1180 - 1184,2009 .

[4] Ajai Gupta, R. P. Saini, and M. P. Sharma "Computerized Modelling of Hybrid Energy System Part III: Study With Simulation Case Results " IEEE Alternate Hydro Energy Centre, India 5th International Conference, ICECE ,Dhaka, 20-22 Dec. 2008.

[5] Barsoum, N.N. Vacent, P. "Balancing Cost, Operation and Performance in Integrated Hydrogen Hybrid Energy System", IEEE The First Asia International Conference on Modelling \& simulation (AMS'07). Page(s) 14-18,2007.

[6] Clint (Jito) Coleman "Hybrid power system operational test results wind/pv/diesel system documentation" IEEE Balancing Cost, Operation and Performance in Integrated Hydrogen Hybrid Energy pp:15.2/1 - 15.2/7 vol.2 1989.

[7] Fabio Morea, Giorgio Viciguerra, Daniele Cucchi, Catalina Valencia "Life Cycle Cost Evaluation of Off-Grid PV-Wind Hybrid Power Systems" Calzavara Spa - s.s. 13 Pontebbana, Basiliano (UD), Itlay Labor srl - Area Science Park, Trieste, Italy 2007 IEEE.

[8] Gianni Celli, Emilio Ghiani, Massimo Loddo, Fabrizio Pilo, Simone Pani "Optimal Location of Biogas and Biomass Generation Plants" Universities Power Engineering Conference, UPEC . IEEE 43rd International, pp:1 - 6,2008.

[9] Guangming LI, Yuanrui CHEN, Tao LI "The Realization of Control Subsystem in the Energy Management of Wind/Solar Hybrid Power System" IEEE 3rd International Conference on Power Electronics Systems and Applications, 2009

[10] Hooman Dehbonei, Chem v. Nayar, Liuchen Chang “A New Modular Hybrid Power system” IEEE Industrial Electronics, ISIE '03. IEEE International Symposium pp:985 - 990 ,vol. 2,2003

[11] J.T. Bialasiewicz, E. Muljadi, S. Drouilhet, G. Nix "Hybrid Power Systems with Diesel and Wind Turbine Generation", IEEE American Control Conference, Proceedings of the pp:1705-1709 vol 3, 1998.

[12] Janani Chakravarthi "Biogas and energy production from cattle waste" IEEE Energy Conversion Engineering Conference, IECEC-97 32nd Intersociety pp:648 - 651 vol.1.1997.

[13] JIANG Yao-hua, XIONG Shu-sheng*1, SHI Wei1, HE Wen-hua1, ZHANG Tian1, LIN Xian-ke, GU Yun,LV Yin-ding, QIAN Xiaojun, YE Zong-yin, WANG Chong-ming, Wang Bei "Research of Biogas as Fuel for Internal Combustion Engine” ,IEEE power and Energy Engineering Conference, APPEEC . Asia-Pacific $2009: 1$ - 4, 2009.

[14] Li Wang, Senior Member, IEEE, and Ping-Yi Lin "Analysis of a Commercial Biogas Generation System Using a Gas EngineInduction Generator Set" IEEE Transactions on Energy Conversion, pp;230-239,Vol. 24, No. 1,2009.

[15] Mayank Aggarwal and Vijit Gupta, "Biogas as Future Prospect for Energy Dependency and Rural Prosperity in India: Statistical Analysis and Economic Impact" IEEE Systems and Information Engineering Design Symposium, SIEDS ' pp: 45 - 48, 2009.

[16] Miss.A.Mazumdar "consolidation of information" hand book pilot edition Tata energy Research Institute General information program and UNISIST United Nations Educational Scientists and Cultural Organization.

[17] Slkyung Kim Changbong Kim Jinsoo Song Gwonjong Yu Youngseok Jung "load sharing operation of 14 kw photovoltaic/wind hybrid power system" IEEE Photovoltaic Specialists Conference, 1997., Conference Record of the Twenty-Sixth E pp:1325 - 1328 ,1997

[18] Steven Durand, Andrew Rosenthal "Photovoltaic hybrid system performance comparison" Southwest Technology Development Institute, Las Cruces, NM Mike Thomas, Sandia National Laboratories, Albuquerque, 1996 IEEE.1996

[19] S.Hasan Saeed, D.K.Sharma "Non Conventional Energy Resources" Publication kataria

[20] Tao CHEN, Jin Ming YANG "Research on Energy Management for Wind/PV Hybrid Power System" School of Electric Power, IEEE 3rd International Conference on Power Electronics Systems and Applications,2009.

[21] Vicente Salas and Emilio Olias Miguel Rascbn, Manuel Vbquez and Carlos Quiiiones "Hybrid Powering System for Stand-Alone Remote Telecom Applications" Telecommunications Energy Conference, IEEE INTELEC. Twenty-second International.

[22] Weidong Gu, Chufu Li, Ming Gu "Study on the Wind/Biogas Integration System for Power Generation and Gas Supply" IEEE World Non-Grid-Connected Wind Power andEnergy Conference, WNWEC ,pp:1 - 4, 2009

[23] Yuanrui Chen and Jie Wu "Agent-Based Energy Management and Control of a Grid- Connected Wind/Solar Hybrid Power System" China The research work is supported by the key project of the National Natural Science Foundation of China under Grant No.60534040.IEEE and sons[2006-2007]

[24] Zhang Yanning, Kang Longyun, Cao Binggang, Huang Chung-Neng, Wu Guohong "Renewable Energy Distributed Power System 
With Wind Power and Biogas Generator" IEEE Transmission \& Distribution Conference \& Exposition: Asia and Pacific, 2009 pp:1 6,2009 .

[25] Zhang Yanning, Kang Longyun, Cao Binggang, Huang Chung-Neng, Wu Guohong "Simulation of Biogas Generation" IEEE T\&D Transmission \& Distribution Conference \& Exposition: Asia and Pacific, pp:1 - 5 ,2009. pp: 311 - 316 .2000.

[26] Zhanping You, Shijun You1, Xianli Li, and Changsheng Hao "Biogas Power Plants Waste Heat Utilization Researches, IEEE Power Electronics and Motion Control Conference IPEMC 6th International pp:2478 -2481,2009[18] 